\title{
Clinical potential of meningioma genomic insights: a practical review for neurosurgeons
}

\author{
Michael Karsy, MD, PhD, MS, ${ }^{1}$ Mohammed A. Azab, MD, ${ }^{1}$ Hussam Abou-Al-Shaar, MD, ${ }^{1}$ \\ Jian Guan, MD, ${ }^{1}$ llyas Eli, MD, ${ }^{1}$ Randy L. Jensen, MD, PhD, ${ }^{1,2}$ and D. Ryan Ormond, MD ${ }^{3}$ \\ 1Department of Neurosurgery, Clinical Neurosciences Center, and ${ }^{2 H}$ untsman Cancer Institute, University of Utah, Salt Lake City, \\ Utah; and ${ }^{3}$ Department of Neurosurgery, University of Colorado School of Medicine, Aurora, Colorado
}

\begin{abstract}
Meningiomas are among the most common intracranial pathological conditions, accounting for $36 \%$ of intracranial lesions treated by neurosurgeons. Although the majority of these lesions are benign, the classical categorization of tumors by histological type or World Health Organization (WHO) grade has not fully captured the potential for meningioma progression and recurrence. Many targeted treatments have failed to generate a long-lasting effect on these tumors. Recently, several seminal studies evaluating the genomics of intracranial meningiomas have rapidly changed the understanding of the disease. The importance of NF2 (neurofibromin 2), TRAF7 (tumor necrosis factor [TNF] receptor-associated factor 7), KLF4 (Kruppel-like factor 4), AKT1, SMO (smoothened), PIK3CA (phosphatidylinositol-4,5-bisphosphate 3-kinase catalytic subunit alpha), and POLR2 (RNA polymerase II subunit A) demonstrates that there are at least 6 distinct mutational classes of meningiomas. In addition, 6 methylation classes of meningioma have been appreciated, enabling improved prediction of prognosis compared with traditional WHO grades. Genomic studies have shed light on the nature of recurrent meningioma, distinct intracranial locations and mutational patterns, and a potential embryonic cancer stem cell-like origin. However, despite these exciting findings, the clinical relevance of these findings remains elusive. The authors review the key findings from recent genomic studies in meningiomas, specifically focusing on how these findings relate to clinical insights for the practicing neurosurgeon.
\end{abstract}

https://thejns.org/doi/abs/10.3171/2018.2.FOCUS1849

KEYWORDS meningioma; genomics; NF2; TRAF7; KLF4; AKT1; SMO; PIK3CA; POLR2

$\mathrm{O}$ VER the 80 years since the first description of meningiomas by Cushing and Eisenhardt, ${ }^{29}$ insight into the clinical behavior of these lesions has greatly expanded. Meningiomas occur with an incidence of 7.44 per 100,000 persons, making them one of the most common primary central nervous system tumors, accounting for $36 \%$ of treated intracranial lesions in the population. ${ }^{21}$ Clinical treatment of meningiomas involves a combination of surgery, radiotherapy, chemotherapy, and/or observation. ${ }^{16}$ Whereas the vast majority of meningiomas may be curable with adequate surgical excision (e.g., Simpson grade I resection), a significant minority of tumors remain challenging to treat and predisposed to recurrence..$^{16,17}$ The 15 histological classifications of meningiomas by the World Health Organization (WHO) have recently changed, resulting in shifts in the relative prevalence of grade I (80\%), atypical grade II (15\%-20\%), and anaplastic grade III (1\%-3\%) lesions..$^{18}$ However, current WHO grading of meningiomas, and even the use of the Simpson grading scale, has limitations in predicting recurrence of benign lesions and progression of more aggressive tumors. ${ }^{3,10}$ Recent genomic analyses have shed new light on the tumor subtypes, their behavior, and the potential for novel treatments. Prior studies employing targeted sequencing or immunohistochemical analysis have helped elucidate the genetic underpinning of meningiomas. ${ }^{3,4,22-24}$ Aarhus et al. ${ }^{1}$ summarized genomic findings up to 2010 and cited a lack of consensus and analysis of genomic data clouding generalizable trends in meningiomas. The goal of this review is to discuss the clinical understanding and application of recent whole-genome studies of cranial meningiomas for practicing neurosurgeons.

\section{Methods}

A query of PubMed using searches for "meningioma

ABBREVIATIONS mTOR = mammalian target of rapamycin; PI3K = phosphoinositide 3-kinase; SCNA = somatic copy-number alteration; WHO = World Health Organization.

SUBMITTED January 30, 2018. ACCEPTED February 20, 2018.

INCLUDE WHEN CITING DOI: 10.3171/2018.2.FOCUS1849. 
and genomics" and "meningioma and genome-wide array" generated 58 and 10 studies, respectively. From these results, we evaluated papers published in the field from 2011 to 2018 and relevant citations in those papers. Six key papers were identified and reviewed with reference to the PRISMA (Preferred Reporting Items for Systematic Reviews and Meta-Analyses) statement (http://prismastatement.org/). A search for actively recruiting studies (clinicaltrials.gov) involving "meningioma" identified 24 studies, which were manually evaluated for relevant trials.

\section{Meningioma Mutations}

The 2016 WHO update on central nervous system tumors has placed new emphasis on the importance of tumor mutations for a variety of meningioma histological subtypes (Table 1). ${ }^{18}$ Traditional studies regarding meningiomas have evaluated single genetic changes and their downstream effects. ${ }^{16,23}$ Deletion of neurofibromin 2 (NF2, merlin, schwannomin) can be identified in $50 \%-60 \%$ of patients with meningioma. ${ }^{25}$ Loss of chromosome 22, where NF2 is located, can also be seen in $40 \%-80 \%$ of sporadic meningiomas. NF2 is a cell membrane-bound protein that regulates other cytoskeletal proteins (e.g., paxillin, actin, syntenin) involved in cytoskeletal remodeling, cell-cell adhesion, and cell migration. Loss of NF2 can activate oncogenic pathways, including Ras/mitogenactivated protein kinase, Notch, phosphoinositide 3-kinase (PI3K)/AKT, Hippo, and mTOR (mammalian target of rapamycin). ${ }^{11-13,19,20,26}$ Other mutated tumor suppressors and oncogenes in meningiomas have also been well reviewed..$^{22}$ In addition to the PI3K/AKT pathway, mutations in the Sonic Hedgehog and WNT pathways have been described. ${ }^{22}$ Although these studies have been instrumental in identifying key driver mutations in meningiomas, they have failed to explain the complete behavior of meningiomas or to identify potential targets for treatment. ${ }^{16}$ One advantage of genomic investigations of meningiomas has been in the understanding of these single genetic changes on a broad scale and their implications on the clinical behavior and progression of meningiomas. Another outgrowth of genetic studies has been in identifying tumor subtypes, which may explain why chemotherapeutic approaches have failed by not subgrouping patients enrolled for trials.

\section{Genomic Studies}

Several key genomic studies have helped further our understanding of meningiomas (Tables 2 and 3). A landmark early study by Clark et al. ${ }^{6}$ identified a series of mutations in non-NF2-mutated meningiomas, namely TRAF7 (tumor necrosis factor [TNF] receptor-associated factor 7), KLF4 (Kruppel-like factor 4), AKT1, and $S M O$ (smoothened). This study evaluated 300 meningiomas using genome-wide genotyping and exome sequencing of 50 grade I and II cases along with confirmation in an independent set of 250 cases. Loss of chromosome 22 was identified in $79 \%(\mathrm{n}=237)$ of tumors, and NF2 mutations were seen in $36 \%(\mathrm{n}=108)$ of tumors. Tumors with $T R A F 7, K L F 4$, and AKT1 mutations were distinct from
TABLE 1. Meningioma subtypes and defining molecular features

\begin{tabular}{|c|c|c|c|}
\hline $\begin{array}{l}\text { Histological } \\
\text { Subtype }\end{array}$ & $\begin{array}{l}\text { WHO } \\
2016 \\
\text { Grade }\end{array}$ & WHO 2016 Criteria & $\begin{array}{c}\text { Gene } \\
\text { Mutations }\end{array}$ \\
\hline Meningothelial & I & Mitosis $<4 / 10 \mathrm{hpf}$ & $\begin{array}{c}\text { TRAF7, AKT1, } \\
\text { POLR2A, } \\
\text { PIK3CA }\end{array}$ \\
\hline $\begin{array}{l}\text { Fibrous (fibro- } \\
\text { blastic) }\end{array}$ & I & & NF2 \\
\hline $\begin{array}{l}\text { Transitional } \\
\text { (mixed) }\end{array}$ & I & & $\begin{array}{l}\text { NF2, AKT1, } \\
\text { PIK3CA }\end{array}$ \\
\hline Psammomatous & I & & NF2 \\
\hline Angiomatous & I & & - \\
\hline Microcystic & I & & - \\
\hline Secretory & I & & KLF4, TRAF7 \\
\hline $\begin{array}{l}\text { Lymphoplasma- } \\
\text { cyte-rich }\end{array}$ & 1 & & - \\
\hline Metaplastic & 1 & & - \\
\hline Chordoid & II & $\begin{array}{l}1 \text { of } 4 \text { criteria: Mitosis } \\
4-19 / 19 \text { hpf; choroid } \\
\text { or clear-cell pathology; } \\
\text { brain invasion; } 3 \text { of the } \\
\text { following } 5 \text { histological } \\
\text { features: 1) necro- } \\
\text { sis, 2) high nuclear/ } \\
\text { cytoplastic ratio, 3) } \\
\text { prominent nucleoli, 4) } \\
\text { architectural sheeting, } \\
\text { 5) hypercellularity }\end{array}$ & - \\
\hline Clear cell & II & & SMARCE1 \\
\hline Atypical & II & & $\begin{array}{l}\text { NF2, TRAF7, } \\
\text { AKT1 }\end{array}$ \\
\hline Papillary & III & \multirow{3}{*}{$\begin{array}{l}\text { Mitosis } \geq 20 / 10 \mathrm{hpf} \text {; frank } \\
\text { anaplasia, papillary, } \\
\text { rhabdoid pathology }\end{array}$} & - \\
\hline Rhabdoid & III & & $B A P 1$ \\
\hline $\begin{array}{l}\text { Anaplastic } \\
\text { (malignant) }\end{array}$ & III & & NF2 \\
\hline
\end{tabular}

Adapted with permission from Springer Nature: Nature Reviews Neurology, Advances in meningioma genetics: novel therapeutic opportunities, Preusser et al. Copyright 2018.

those with $N F 2$ or $S M O$ mutations, thus suggesting 3 genomic subclasses of meningiomas, where NF2 and SMO mutations are not likely to co-occur. TRAF7, KLF4, AKT1, and $S M O$ mutations were seen in $25 \%, 10.3 \%, 12.7 \%$, and $3.7 \%$ of meningiomas, respectively. TRAF7 is a multidomain protein, utilizing coproteins such as MEKK3, that regulates signaling along the TNF pathway by acting as an E3 ubiquitin ligase that selectively tags proteins for degradation. KLF4 has best been understood as one of the key transcription factors involved in generating induced pluripotent stem cells. AKT1 showed an activation mutation (peptide E17 K) that results in activation of PI3K/AKT signaling. SMO mutations result in activation of Hedgehog signaling involved in various cancers. All newly identified mutated genes were shown to play roles in a variety of cancers beyond meningiomas. This study also demonstrated greater chromosomal instability in higher-grade 
TABLE 2. Recent key genomic studies in meningiomas

\begin{tabular}{|c|c|c|c|}
\hline Study & Sample & Genomic Platform & Key Genes Identified \\
\hline $\begin{array}{l}\text { Clark et al., } \\
2013\end{array}$ & $\begin{array}{l}300 \text { meningiomas; screening: } 39 \text { grade I, } 11 \\
\text { grade II; validation: } 204 \text { grade I, } 46 \text { grade II }\end{array}$ & $\begin{array}{l}\text { Illumina whole-genome genotyping Nimblegen/ } \\
\text { Roche human solution-capture exome array }\end{array}$ & $\begin{array}{l}\text { NF2, TRAF7, KLF4, AKT1, } \\
\quad \text { SMO }\end{array}$ \\
\hline $\begin{array}{l}\text { Brastianos et } \\
\text { al., } 2013\end{array}$ & $\begin{array}{l}65 \text { tumors (incl } 17 \text { meningiomas); screening: } 18 \\
\text { grade I; validation: } 30 \text { grade I, } 18 \text { grade II or III }\end{array}$ & $\begin{array}{l}\text { Illumina HiSeq 2000; NimbleGen SeqCap EZ Exome } \\
\text { Library SR v2.2; Agilent SureSelect All Exon v2.0 }\end{array}$ & AKT1, SMO \\
\hline $\begin{array}{l}\text { Abedalthagafi } \\
\text { et al., } 2016\end{array}$ & $\begin{array}{l}150 \text { meningiomas; } 104 \text { grade I, } 41 \text { grade II, } 5 \\
\text { grade III }\end{array}$ & $\begin{array}{l}\text { Agilent SurePrint G3 human CGH microarray chip } \\
\text { custom sequencing }\end{array}$ & PI3KCA \\
\hline $\begin{array}{l}\text { Clark et al., } \\
\quad 2016\end{array}$ & 775 meningiomas & $\begin{array}{l}\text { Illumina whole-genome genotyping; Nimblegen/ } \\
\text { Roche human solution-capture exome array }\end{array}$ & $\begin{array}{l}\text { POLR2A, SMARCB1, } \\
\text { AKT3, PIK3CA, PIK3R1, } \\
\text { PRKAR1A, SUFU }\end{array}$ \\
\hline Bi et al., 2017 & 134 high-grade meningiomas (grades II \& III) & $\begin{array}{l}\text { Custom sequencing (Agilent SureSelect hybrid } \\
\text { capture kit w/ Illumina HiSeq } 2500 \text { system) }\end{array}$ & NF2 \\
\hline $\begin{array}{l}\text { Sahm et al., } \\
\quad 2017\end{array}$ & $\begin{array}{l}497 \text { meningiomas \& } 309 \text { other extra-axial skull } \\
\text { tumors }\end{array}$ & $\begin{array}{l}\text { Illumina Human Methylation 450k BeadChip \& 850k } \\
\text { EPIC }\end{array}$ & Methylation classes \\
\hline
\end{tabular}

$\mathrm{CGH}=$ comparative genomic hybridization .

meningiomas, a finding that helped to further elucidate the mechanism by which lower-grade meningiomas progress. Finally, this study helped delineate various mutations and the site of tumor origin (Fig. 1): lateral and posterior skull base (NF2 or chromosome 22 loss), sphenoid wing and midline skull base (KLF4/TRAF7), anterior midline skull base (AKT1/TRAF7), and midline anterior fossa (SMO). Overall, this early study helped elucidate different genetic subtypes of meningioma at a time when only single-mutational changes, histological type, or WHO grade were distinguishing factors between patients.

Another critical genomic study by Brastianos et al. ${ }^{5}$ confirmed the presence of $A K T 1$ and SMO mutations in meningiomas. Here, screening of 17 meningiomas with whole-genome and whole-exome sequencing was confirmed with focused sequencing of 48 additional tumors. Interestingly, the median somatic copy-number alteration (SCNA) rate was $3.3 \%$ of the genome, which was approximately 10 times lower than the average for other tumors. This suggested that meningiomas develop a low number of mutations, but these are important and ultimately affect their development. Of course, not only the low mitotic rate of meningiomas could generate such a pattern, but previous treatments, such as the radiotherapy that some of

TABLE 3. Key genes identified using recent genomic platforms in meningiomas

\begin{tabular}{|c|c|c|c|c|}
\hline Gene & Mutated Gene Name & Gene Function & Tumor Location in Meningiomas & Reference \\
\hline NF2 & $\begin{array}{l}\text { Merlin, schwannomin, } \\
\text { moesin-, ezrin-, radixin } \\
\text { [ERM]-like protein }\end{array}$ & $\begin{array}{l}\text { Cell membrane-bound protein that } \\
\text { regulates other cytoskeletal proteins } \\
\text { involved w/ various cell activities }\end{array}$ & $\begin{array}{l}\text { Lateral and pst skull base (low- } \\
\text { grade); parasagittal, falcine, } \\
\text { torcula, \& intraventricular } \\
\text { regions (high-grade) }\end{array}$ & $\begin{array}{l}\text { Brastianos et al., 2013; Clark et } \\
\text { al., 2013; Clark et al., 2016; } \\
\text { Abedalthagafi et al., 2016; Bi et } \\
\text { al., } 2017\end{array}$ \\
\hline TRAF7 & $\begin{array}{l}\text { Tumor necrosis factor } \\
\text { [TNF] receptor-associ- } \\
\text { ated factor } 7\end{array}$ & $\begin{array}{l}\text { Multidomain protein, regulates TNF } \\
\text { pathway signaling, E3 ubiquitin } \\
\text { ligase, regulates MEKK33 }\end{array}$ & Same as KLF4 \& AKT1 & $\begin{array}{l}\text { Clark et al., 2013; Clark et al., } \\
\text { 2016; Abedalthagafi et al., } 2016\end{array}$ \\
\hline KLF4 & Kruppel-like factor 4 & $\begin{array}{l}\text { Involved in induced pluripotent stem } \\
\text { cells }\end{array}$ & $\begin{array}{l}\text { Sphenoid wing \& midline skull } \\
\text { base }\end{array}$ & $\begin{array}{l}\text { Clark et al., 2013; Clark et al., } \\
\text { 2016; Abedalthagafi et al., } 2016\end{array}$ \\
\hline AKT1 & & Activation of PI3K/AKT signaling & Ant midline skull base & $\begin{array}{l}\text { Brastianos et al., 2013; Clark et } \\
\text { al., 2013; Clark et al., 2016; } \\
\text { Abedalthagafi et al., } 2016\end{array}$ \\
\hline SMO & Smoothened & Activation of Hedgehog signaling & Midline ant fossa & $\begin{array}{l}\text { Brastianos et al., 2013; Clark et } \\
\text { al., 2013; Clark et al., 2016; } \\
\text { Abedalthagafi et al., } 2016\end{array}$ \\
\hline PIK3CA & $\begin{array}{l}\text { Phosphatidylinositol-4,5- } \\
\text { bisphosphate 3-kinase } \\
\text { catalytic subunit alpha }\end{array}$ & Activation of PI3K/AKT pathway & Ant \& middle skull base & Abedalthagafi et al., 2016 \\
\hline POLR2 & $\begin{array}{l}\text { RNA polymerase II } \\
\text { subunit A }\end{array}$ & $\begin{array}{l}\text { Regulator of DNA polymerase interac- } \\
\text { tion w/ transcription factor } 2 \mathrm{~B} \text { during } \\
\text { pre-initiation complex formation }\end{array}$ & Ant skull base & Clark et al., 2016 \\
\hline
\end{tabular}



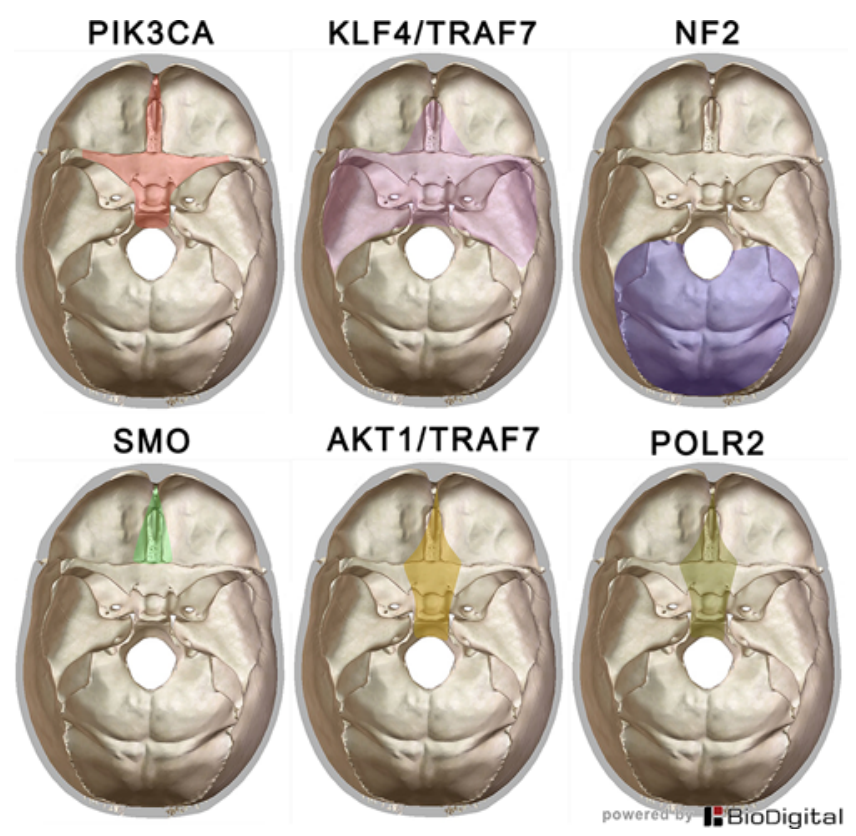

FIG. 1. Meningioma tumor locations and reported gene mutations. Mutations identified in genomic studies of meningioma and tumor areas of formation are shown. Images obtained from https://www.biodigital. $\mathrm{com} /$ were modified with permission to illustrate results from Clark et al., 2013; ${ }^{6}$ Clark et al., 2016; ${ }^{7}$ and Abedalthagafi et al., 2016. ${ }^{2}$

the patients had received in this study prior to evaluation, could also result in this pattern. Higher-grade meningiomas had a median SCNA rate of $12.3 \%$ and higher rates of chromothripsis (large chromosomal rearrangements), approximating some of the features seen in other types of aggressive cancers. In addition to NF2, AKT1, and SMO predominant mutations, a variety of mutations not previously described were noted. Although many of these genes had previously identified roles in cancer, their roles in meningiomas were unclear and warranted additional investigation. In addition, $8 \%$ of tumors showed alterations in epigenetic modifiers, which were previously unexplored in meningiomas on a genomic scale, suggesting they may play an important role.

Abedalthagafi et al. ${ }^{2}$ performed high-resolution arraycomparative genomic hybridization in 150 meningiomas and characterized the importance of PIK3CA mutations in $7 \%$ of non-NF2-mutated meningiomas. PIK3CA mutations in meningioma have been suggested to increase activation of the PI3K/AKT pathway, known to be involved in cancer proliferation, protein synthesis, and migration. In their study, Abedalthagafi et al. showed that PIK3CA mutations co-localized with TRAF7 mutations but not $N F 2, A K T 1$, or $S M O$ mutations. In addition, they found that tumors with PIK3CA mutations arose from the anterior tuberculum sellae, sphenoid wing, and clival regions. All lesions in their study were WHO grade I but showed features of more aggressive meningiomas. Although this study was not the first to suggest PIK3CA mutations in meningioma, it did categorize this mutation in a large set of meningiomas, evaluated tumor location, and highlighted PIK3CA mutation patterns in the context of other mutational patterns.
A follow-up study by Clark et al. ${ }^{7}$ uncovered the importance of POLR2A (RNA polymerase II subunit A) and other mutations in meningiomas. POLR2A mutations, which were seen in $6 \%$ of benign meningiomas, were a distinct subclass from prior genomic tumor subtypes, with localization to the anterior skull base. POLR2A affects the interaction of DNA polymerase with transcription factor $2 \mathrm{~B}$ during the pre-initiation complex where, in meningiomas, it was suggested to play a widespread role in altering gene expression. A total of 23 samples of 775 total tumors, not showing any previous mutational pattern, were evaluated, and the presence of POLR2A alterations was uncovered exclusively in benign tumors. Further investigation indicated that $P O L R 2 A$ alters WNT signaling pathways and transcription factors. This study also explored genes previously unknown in meningiomas, including SMARCBI (SWI/ SNF-related matrix-associated actin-dependent regulator of chromatin subfamily B member 1), AKT3, PIK3CA, PI$K 3 R 1, P R K A R 1 A$ (protein kinase CAMP-dependent type I regulatory subunit alpha), and $S U F U$ (suppressor of fused homolog). "Super-enhancer regions," that is genomic regions with high levels of histone 3 lysine 27 acetylation, were found to support a number of upregulated transcription factors in broad segments of meningiomas, such as FOX proteins, HDACs, KLF2 and KLF4, WNT proteins, and BCL2. Because of the importance of these factors as important regulators of embryonic stem cell development and signaling, these findings suggest that meningiomas may derive from an early progenitor or cancer stem cell.

Whereas prior studies centered on low-grade meningiomas, Bi et al. ${ }^{4}$ analyzed 134 high-grade meningiomas to compare rates of NF2 mutation, chromosomal abnormalities, and distinct changes with those of low-grade meningiomas. Whole-genome sequencing or whole-exome sequencing, including discovery and validation stages, also captured lesions with multiple recurrences. A mean mutation rate of 23 per sample was identified, which was much higher than in low-grade meningiomas and comparable with the mutation rate in thyroid cancer or craniopharyngiomas but lower than those of head and neck tumors, colorectal cancer, and melanomas. NF2 mutation or loss of chromosome 22 was found in $80 \%$ of samples, while other mutations (TRAF7, KLF4, AKT1, and SMO) were not significantly present. In addition, high-grade meningiomas showed a higher rate of genomic disruption than low-grade meningiomas (19\% vs 3\%) and higher rates of genomic rearrangements, resembling aggressive tumors such as glioblastoma. Samples from patients who had been treated with radiation had a higher mean rate of mutation than nonirradiated samples (23 vs 14 ) and a higher rate of copy number alterations. Mechanisms suggested to promote the high level of genomic disorganization in highgrade meningiomas included mutation in tumor suppressor p53, a key DNA-repair modulating protein, and faulty DNA repair pathways. Significant heterogeneity of mutations was seen among high-grade meningiomas, with only $23 \%$ of mutations shared overall. Heterogeneity was also seen within individual patient tumors in multiple samples obtained over time. For patients who underwent multiple resections over time, genomic comparison of resected tumor specimens showed that recurrent lesions had sig- 
nificantly distinct genomes from the previously resected lesions, suggesting that recurrences were in fact arising from unique, unresected tumors rather than residual, parent tumor. High-grade meningiomas were more likely to be from parasagittal, falcine, torcular, and intraventricular regions rather than the skull base. Although fewer targetable pathways for treatment were identified (AKT1, SMO, PIK3CA) than in lower-grade meningiomas, higher rates of potentiation neoantigens - that is, targets potentially useful for immunotherapy-were found. These findings suggest that single-targeted therapy might not be as successful as immune-driven approaches, immunomodulators (e.g., PD-1 inhibitors), or pan-targeted approaches in highgrade meningiomas.

\section{Methylation Studies}

Sahm et al. ${ }^{27}$ analyzed DNA methylation in 497 meningiomas compared with that of 309 extraaxial skull tumors in a multicenter European cohort and developed 6 clinically distinct mutational classes, which were more accurate in predicting clinical courses than WHO grade. Meningioma samples segregated from other tumors during unsupervised clustering analysis, suggesting distinct genomic patterns compared with other tumors. The groups were designated as methylation benign classes $1-3$, methylation intermediate classes $\mathrm{A}$ and $\mathrm{B}$, and methylation malignant, with each class enriching for more aggressive WHO grade tumors. Interestingly, recurrent tumors maintained the same methylation pattern and group. NF2 mutations were seen in a portion of all methylation classes except benign class 2 where non-NF2 mutations (TRAF7, AKT1, KLF4, $S M O$, and $P I K 3 C A$ ) were predominant. Intermediate and malignant classes were enriched for $N F 2$ and various chromosomal abnormalities. Significant overlaps of all methylation classes and histological types were seen; however, more aggressive tumor histologies (e.g., choroid, atypical, anaplastic, rhabdoid, and papillary) were more common in intermediate and malignant methylation classes. Kaplan-Meier survival curves were more accurately predicted by methylation classes than by WHO grade, with accuracy that increased over patient follow-up time. In fact, methylation patterns could help identify subgroups of patients with WHO grade I tumors that progressed and patients with WHO Grade II tumors that remained stable. In addition, Simpson grade I resection was not an independent predictor of recurrence, unlike methylation class, suggesting that tumor biology can significantly affect disease freedom.

\section{Clinical Implications}

Findings from genomic studies have dramatically shifted our understanding of meningiomas; however, the clinical application of this knowledge has yet to occur. Subcategorization of meningiomas by genetic mutations or methylation class and prediction of prognosis have not progressed beyond a research paradigm. In addition, tumor classification into genomic patterns by location has yet to change surgical decision-making. Maximal resection with preservation of neurovascular structures and patient assessment on a case-by-case basis remains the modus ope- randi. Whole-genome sequencing does have some limitations in that the accuracy of gene expression depends on known gene sequences, often disregards noncoding DNA, and does not always correlate gene expression to protein action. The combination of gene platforms will ultimately be necessary to understand meningioma pathology.

Radiological assessment of meningiomas to predict histological class, WHO grade, or genomic patterns is an exciting and developing field. Coroller et al. ${ }^{8}$ evaluated 15 quantitative and 10 qualitative radiological features of 175 meningiomas; these features were more accurate than clinical features in predicting tumor behavior. Increased necrosis, intratumoral heterogeneity, nonspherical shape, and larger volumes predicted higher-grade lesions. Other advanced imaging modalities, such as fractal-based analysis ${ }^{9,14,15}$ as well as diffusion MRI, MR elastography, and MR spectroscopy, ${ }^{28,30}$ have been employed to predict meningioma aggressiveness. Imaging analysis may complement genomic categorization to impact surgical decisionmaking.

The emergence of meningioma genomics has led to a number of current clinical trials aiming to improve treatment by targeting mutational class (Fig. 2). The Alliance for Clinical Trials in Oncology Group and National Cancer Institute are currently recruiting patients with residual or progressive meningioma for screens of $A K T 1$, $S M O$, or $N F 2$ mutations and treatment with AKT, SMO, and FAK (focal adhesion kinase) inhibitors, respectively (NCT02523014). An inhibitor of SMO, namely vismodegib, has previously been approved for treatment of basal cell carcinoma and is currently in trial for $S M O$-mutated meningiomas (NCT02523014). Trials of dual mTORC1 and mTORC2 inhibitors (AZD2014) (NCT03071874 and NCT02831257) and the BRAF inhibitor nivolumab (NCT02648997 and NCT03173950) are being initiated in meningiomas. Immunomodulating therapies, such as the programmed cell death 1 inhibitor pembrolizumab, are also currently in trials (NCT03279692). It remains to be seen whether targeting of these genes in specific tumor classes will affect outcome.

\section{Conclusions}

Recent genomic studies have uncovered novel findings regarding meningiomas. The importance of $N F 2, T R A F 7$, KLF4, AKT1, SMO, PI3KCA, and POLR2A mutations, among others, has been shown. Genomic subclasses with implications for tumor location and a possible embryonic-like cancer stem cell of origin have been identified. Aggressive, high-grade meningiomas have shown predominant NF2 mutations with greater genomic disorganization than lower-grade tumors. Methylation patterns and 6 unique subclasses have shown better prediction of patient outcome than traditional WHO grading. These genomic findings will likely affect the subsequent round of WHO tumor categorization. Clinical trials currently in progress are beginning to use genomic subclass information to drive therapy. Ultimately, time will tell how, rather than if, these findings will be integrated into clinical practice. 


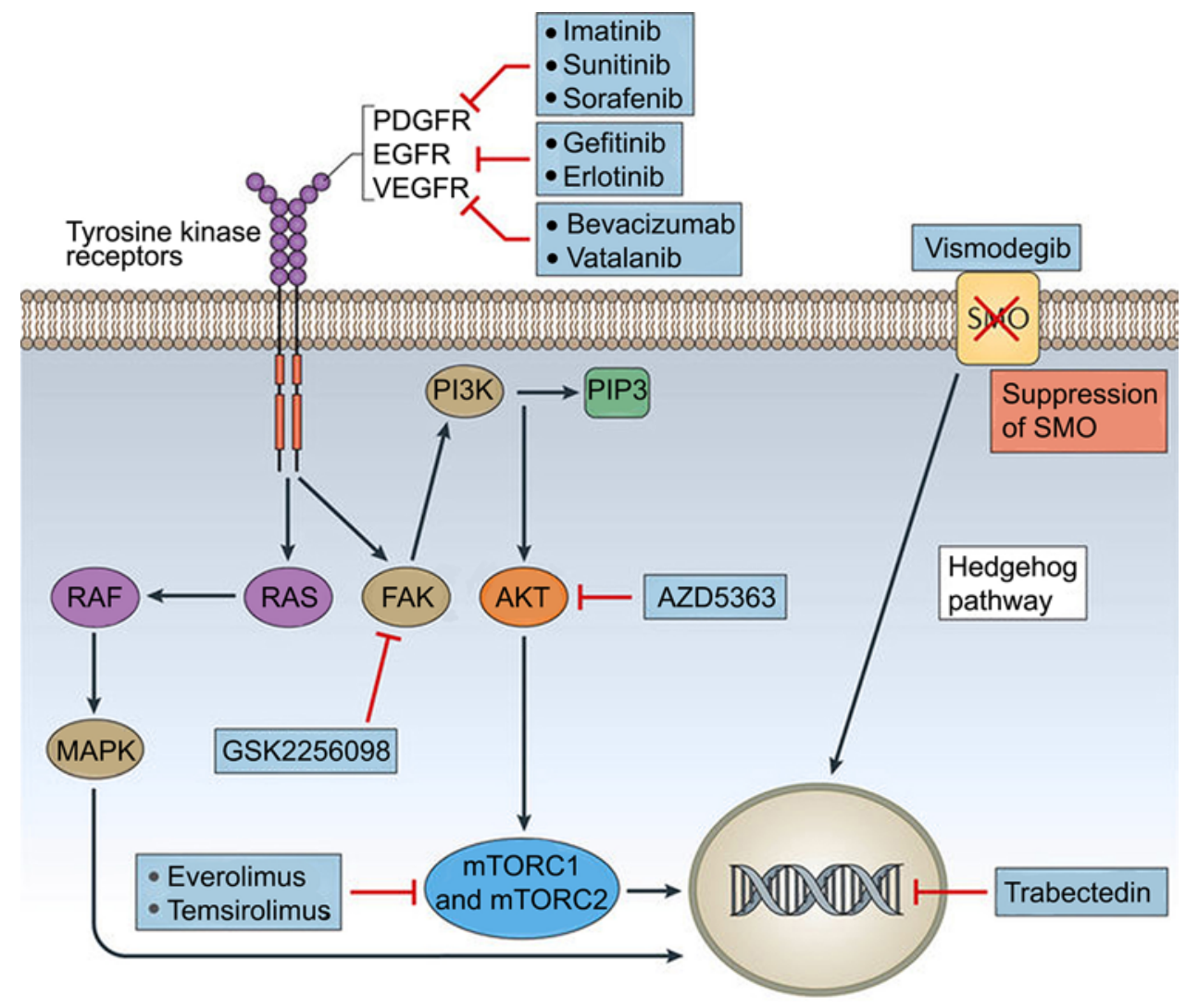

Nature Reviews | Neurology

FIG. 2. Signaling pathways and potential targets implicated in meningiomas. Major signaling pathways involved in meningiomas include the MAPK (mitogen-activated protein kinase) pathway, PI3K (phosphoinositide-3-kinase)/AKT/mammalian target of rapamycin (mTOR) complex pathway, and the Hedgehog pathway. Current treatment targets include a mix of approved and experimental therapies. EGFR = epidermal growth factor receptor; FAK = focal adhesion kinase; PDGFR = platelet-derived growth factor receptor; PIP3 = phosphatidylinositol 3,4,5-triphosphate; SMO = smoothened homolog; VEGFR = vascular endothelial growth factor receptor. Reproduced with permission from Springer Nature: Nature Reviews Neurology, Advances in meningioma genetics: novel therapeutic opportunities, Preusser et al. Copyright 2018.

\section{References}

1. Aarhus M, Lund-Johansen M, Knappskog PM: Gene expression profiling of meningiomas: current status after a decade of microarray-based transcriptomic studies. Acta Neurochir (Wien) 153:447-456, 2011

2. Abedalthagafi M, Bi WL, Aizer AA, Merrill PH, Brewster R, Agarwalla PK, et al: Oncogenic PI3K mutations are as common as AKT1 and SMO mutations in meningioma. Neuro Oncol 18:649-655, 2016

3. Bi WL, Abedalthagafi M, Horowitz P, Agarwalla PK, Mei Y, Aizer AA, et al: Genomic landscape of intracranial meningiomas. J Neurosurg 125:525-535, 2016

4. Bi WL, Greenwald NF, Abedalthagafi M, Wala J, Gibson WJ, Agarwalla PK, et al: Genomic landscape of high-grade meningiomas. NPJ Genom Med 2:15, 2017

5. Brastianos PK, Horowitz PM, Santagata S, Jones RT, McKenna A, Getz G, et al: Genomic sequencing of meningiomas identifies oncogenic SMO and AKT1 mutations. Nat Genet 45:285-289, 2013

6. Clark VE, Erson-Omay EZ, Serin A, Yin J, Cotney J, Ozduman K, et al: Genomic analysis of non-NF2 meningiomas reveals mutations in TRAF7, KLF4, AKT1, and SMO. Science 339:1077-1080, 2013

7. Clark VE, Harmancı AS, Bai H, Youngblood MW, Lee TI,
Baranoski JF, et al: Recurrent somatic mutations in POLR2A define a distinct subset of meningiomas. Nat Genet 48:12531259,2016

8. Coroller TP, Bi WL, Huynh E, Abedalthagafi M, Aizer AA, Greenwald NF, et al: Radiographic prediction of meningioma grade by semantic and radiomic features. PLoS One 12:e0187908, 2017

9. Di Ieva A, Le Reste PJ, Carsin-Nicol B, Ferre JC, Cusimano MD: Diagnostic value of fractal analysis for the differentiation of brain tumors using 3-Tesla magnetic resonance susceptibility-weighted imaging. Neurosurgery 79:839-846, 2016

10. Goldbrunner R, Minniti G, Preusser M, Jenkinson MD, Sallabanda K, Houdart E, et al: EANO guidelines for the diagnosis and treatment of meningiomas. Lancet Oncol 17:e383e391, 2016

11. Hamaratoglu F, Willecke M, Kango-Singh M, Nolo R, Hyun E, Tao C, et al: The tumour-suppressor genes NF2/Merlin and Expanded act through Hippo signalling to regulate cell proliferation and apoptosis. Nat Cell Biol 8:27-36, 2006

12. James MF, Han S, Polizzano C, Plotkin SR, Manning BD, Stemmer-Rachamimov AO, et al: NF2/merlin is a novel negative regulator of mTOR complex 1 , and activation of mTORC1 is associated with meningioma and schwannoma growth. Mol Cell Biol 29:4250-4261, 2009 
13. James MF, Stivison E, Beauchamp R, Han S, Li H, Wallace $M R$, et al: Regulation of mTOR complex 2 signaling in neurofibromatosis 2-deficient target cell types. Mol Cancer Res 10:649-659, 2012

14. Jensen R, Lee J: Predicting outcomes of patients with intracranial meningiomas using molecular markers of hypoxia, vascularity, and proliferation. Neurosurgery 71:146-156, 2012

15. Karsy M, Burnett B, Di Ieva A, Cusimano MD, Jensen RL: Microvascularization of Grade I meningiomas: effect on tumor volume, blood loss, and patient outcome. J Neurosurg 128:657-666, 2018

16. Karsy M, Guan J, Cohen A, Colman H, Jensen RL: Medical management of meningiomas: current status, failed treatments, and promising horizons. Neurosurg Clin N Am 27:249-260, 2016

17. Karsy M, Hoang N, Barth T, Burt L, Dunson W, Gillespie DL, et al: Combined hydroxyurea and verapamil in the clinical treatment of refractory meningioma: human and orthotopic xenograft studies. World Neurosurg 86:210-219, 2016

18. Louis DN, Perry A, Reifenberger G, von Deimling A, Figarella-Branger D, Cavenee WK, et al: The 2016 World Health Organization Classification of Tumors of the Central Nervous System: a summary. Acta Neuropathol 131:803-820, 2016

19. Mei Y, Du Z, Hu C, Greenwald NF, Abedalthagafi M, Agar NYR, et al: Osteoglycin promotes meningioma development through downregulation of NF2 and activation of mTOR signaling. Cell Commun Signal 15:34, 2017

20. Morrison H, Sperka T, Manent J, Giovannini M, Ponta H, Herrlich P: Merlin/neurofibromatosis type 2 suppresses growth by inhibiting the activation of Ras and Rac. Cancer Res 67:520-527, 2007

21. Ostrom QT, Gittleman H, Fulop J, Liu M, Blanda R, Kromer C, et al: CBTRUS Statistical Report: Primary Brain and Central Nervous System Tumors Diagnosed in the United States in 2008-2012. Neuro Oncol 17 (Suppl 4):iv1-iv62, 2015

22. Pham MH, Zada G, Mosich GM, Chen TC, Giannotta SL, Wang K, et al: Molecular genetics of meningiomas: a systematic review of the current literature and potential basis for future treatment paradigms. Neurosurg Focus 30(5):E7, 2011

23. Preusser M, Brastianos PK, Mawrin C: Advances in meningioma genetics: novel therapeutic opportunities. Nat Rev Neurol 14:106-115, 2018

24. Ragel BT, Jensen RL: Aberrant signaling pathways in meningiomas. J Neurooncol 99:315-324, 2010
25. Ragel BT, Jensen RL: Molecular genetics of meningiomas. Neurosurg Focus 19(5):E9, 2005

26. Rong R, Tang X, Gutmann DH, Ye K: Neurofibromatosis 2 (NF2) tumor suppressor merlin inhibits phosphatidylinositol 3-kinase through binding to PIKE-L. Proc Natl Acad Sci U S A 101:18200-18205, 2004

27. Sahm F, Schrimpf D, Stichel D, Jones DTW, Hielscher T, Schefzyk S, et al: DNA methylation-based classification and grading system for meningioma: a multicentre, retrospective analysis. Lancet Oncol 18:682-694, 2017

28. Shiroishi MS, Cen SY, Tamrazi B, D'Amore F, Lerner A, King KS, et al: Predicting meningioma consistency on preoperative neuroimaging studies. Neurosurg Clin N Am 27:145-154, 2016

29. Shrivastava RK, Segal S, Camins MB, Sen C, Post KD: Harvey Cushing's Meningiomas text and the historical origin of resectability criteria for the anterior one third of the superior sagittal sinus. J Neurosurg 99:787-791, 2003

30. Yao A, Pain M, Balchandani P, Shrivastava RK: Can MRI predict meningioma consistency?: a correlation with tumor pathology and systematic review. Neurosurg Rev [epub ahead of print], 2016

\section{Disclosures}

Dr. Jensen reports a consultant relationship with Medtronic. Dr. Ormond reports receipt of support for non-study-related clinical or research effort from Synaptive.

\section{Author Contributions}

Conception and design: Ormond, Karsy. Drafting the article:

Karsy, Azab. Critically revising the article: all authors. Reviewed submitted version of manuscript: all authors. Approved the final version of the manuscript on behalf of all authors: Ormond.

\section{Supplemental Information Current Affiliations}

Dr. Abou-Al-Shaar: Department of Neurosurgery, Hofstra Northwell School of Medicine, Manhasset, NY.

\section{Correspondence}

D. Ryan Ormond: University of Colorado School of Medicine, Aurora, CO.david.ormond@ucdenver.edu. 